\title{
Multidisciplinary rehabilitation program: effects of a multimodal intervention for patients with Alzheimer's disease and cognitive impairment without dementia
}

\author{
Glenda Dias Santos'1, Paula Villela Nunes1, Florindo Stella 1 1,2, Paula Schimidt Brum³, Monica Sanches Yassuda 2,3 , \\ Linda Massako Ueno ${ }^{4}$, Wagner Farid GattaZ ${ }^{1}$, Orestes Vicente Forlenza ${ }^{1}$
}

\author{
1 Laboratory of Neuroscience (LIM-27), Department and Institute of Psychiatry, Faculty of Medicine, University of São Paulo, São Paulo, SP, Brazil. \\ 2 Universidade Estadual Paulista (Unesp), Biosciences Institute, Rio Claro, SP Brazil. \\ ${ }^{3}$ Department of Neurology, Faculty of Medicine, University of São Paulo, São Paulo, SP, Brazil. \\ ${ }^{4}$ School of Arts, Sciences and Humanities, University of São Paulo, São Paulo, SP, Brazil.
}

Received: 10/27/2015 - Accepted: 11/9/2015

DOl: 10.1590/0101-60830000000066

\begin{abstract}
Background: Non-pharmalogical interventions represent an important complement to standard pharmalogical treatment in dementia. Objective: This study aims to evaluate the effects of a multidisciplinary rehabilitation program on cognitive ability, quality of life and depression symptoms in patients with Alzheimer's disease (AD) and cognitive impairment without dementia (CIND). Methods: Ninety-seven older adults were recruited to the present study. Of these, 70 patients had mild $\mathrm{AD}$ and were allocated into experimental $(\mathrm{n}=54)$ or control $(\mathrm{n}=16)$ groups. Two additional active comparison groups were constituted with patients with moderate $\operatorname{AD}(n=13)$ or with $\operatorname{CIND}(\mathrm{n}=14)$ who also received the intervention. The multidisciplinary rehabilitation program lasted for 12 weeks and was composed by sessions of memory training, recreational activities, verbal expression and writing, physical therapy and physical training, delivered in two weekly 6-hour sessions. Results: As compared to controls, mild AD patients who received the intervention had improvements in cognition $(\mathrm{p}=0.021)$ and quality of life $(\mathrm{p}=0.003)$, along with a reduction in depressive symptoms $(\mathrm{p}<0.001)$. As compared to baseline, CIND patients displayed at the end of the intervention improvements in cognition $(p=0.005)$ and depressive symptoms $(p=0.011)$. No such benefits were found among patients with moderate AD. Discussion: This multidisciplinary rehabilitation program was beneficial for patients with mild AD and CIND. However, patients with moderate dementia did not benefit from the intervention.
\end{abstract}

Santos GD et al. / Arch Clin Psychiatry. 2015;42(6):153-6

Keywords: Alzheimer disease, impairment cognitive without dementia, multimodal intervention, multidisciplinary rehabilitation program.

\section{Introduction}

Non-pharmacological interventions represent an important complement to standard pharmacological treatment in dementia. Cognitive, physical and psychosocial rehabilitation may improve global function, mental state and quality of life ${ }^{1-3}$. These interventions may further reduce social costs 4 . Different approaches have been proposed such as cognitive rehabilitation, occupational therapy, physical activity, music therapy, art therapy and others interventions $s^{5,6}$.

These non-pharmacological interventions may be delivered separately or in the format of combined, multimodal interventions ${ }^{7}$. Given the complexity of dementia and the multiple needs displayed by patients and caregivers along the distinct phases of the dementing process, interest in multimodal interventions has increased in the past few years 8 . Several studies have been performed addressing the treatment and prevention of cognitive impairment ${ }^{9-13}$, in samples of older adults with cognitive impairment without dementia (CIND), mild cognitive impairment ${ }^{5,14,15}$ and dementia ${ }^{5,7,15-17}$.

Multimodal intervention for patients with Alzheimer's disease (AD) may help in maintaining cognitive function, community independence, reduction of depression symptoms and improving the quality of life of caregivers ${ }^{5,7}$. In view of the multifactorial causes of $\mathrm{AD}$, multimodal interventions have additive or interactive effects and may prove more effective than single domain interventions ${ }^{8,18,19}$. The aim of this study was to evaluate the effect of a multidisciplinary rehabilitation program on cognitive ability, depression symptoms and quality of life in patients with mild to moderate AD and CIND.

\section{Methods}

\section{Study design}

The present study was a single-blinded intervention trial conducted at a university-based psychogeriatric clinic (Institute of Psychiatry,
University of Sao Paulo, Brazil) to test the efficacy of a clinically oriented multimodal rehabilitation program on global function, cognition and quality of live of elderly patients with cognitive impairment and dementia. Participants were consecutively referred to the rehabilitation unit from the hospital's outpatient clinic, expecting to receive complementary, non-pharmacological treatment for memory and cognitive disorders. All participants signed informed consent and the study was approved by the local Ethical Committee.

\section{Participants}

The total sample consisted of 97 older adults with various degrees of cognitive complaints, ranging from cognitive impairment without dementia (CIND) to mild and moderate dementia due to AD. Participants were assessed upon enrollment by a multidisciplinary team composed by psychiatrists, neurologists, geriatricians, neuropsychologists and occupational therapists. Diagnoses were reached at consensus sessions taking into account all available clinical (medical, neuropsychological and functional) and laboratorial information, including neuroimaging. The diagnosis of probable $\mathrm{AD}$ was established according to the NINCDS-ADRDA criteria ${ }^{20}$. The diagnosis of CIND was established to non-demented elders with neuropsychological evidence of subtle cognitive deficits affecting at least one cognitive domain, in the absence of medical or psychiatric abnormalities and other likely causes of cognitive impairment ${ }^{21,22}$.

$\mathrm{AD}$ patients were included in the study if they had 60 years of age or more and were receiving standard pharmacological treatment with anti-dementia drugs, i.e., stable therapeutic daily doses of cholinesterase inhibitors and/or memantine for at least three months. Mild AD patients were expected to have scores of 17 or more in the Mini-Mental State Examination (MMSE) 23,24 and of 0.5 or 1.0 in the Clinical Dementia Rating Scale (CDR)25,26; for patients with moderate $\mathrm{AD}, \mathrm{MMSE}$ and $\mathrm{CDR}$ scores were expectedly $>13$ and 2.0 
respectively. CIND patients had CDR scores of 0.5 and MMSE scores above the education-corrected cut-off values that separates cases from controls in the Brazilian population ${ }^{23}$.

The majority of the sample comprised patients with mild AD $(\mathrm{n}=70)$, and therefore only participants in this diagnostic group were evaluated in a randomized-coltrolled trial (RCT) format with an experimental group compared to a control group. Due to ethical reasons (i.e., need for treatment) the allocation into intervention or control groups was done at a 3:1 ratio, yielding a total of 54 and 16 patients with mild $\mathrm{AD}$ respectively in the experimental (intervention) and control (waiting list) groups. The remaining 27 patients of the total sample were diagnosed with moderate $\mathrm{AD}(\mathrm{n}=$ 13) or with CIND $(n=14)$. Because these sub-samples of patients were too small to warrant randomization into experimental and control groups, and too different clinically to merge with the former group of mild AD patients, we decided to provide treatment to all of them and regard these sub-samples as active comparison groups, addressing endpoint vs. baseline differences in outcome variables separately.

\section{Outcome variables}

All participants were evaluated at baseline and endpoint by a rater who was blind to group assignment. The assessment battery included: MMSE23,24; Geriatric Depression Scale (GDS) 27,28 and Quality of Life scale for patients with Alzheimer's Disease (QoL-AD) ${ }^{29}$ which the patient evaluates his/her own quality of life (PQoL-AD) and the caregiver/family assesses on the patient's quality of life (CQoL-AD).

\section{Intervention}

The intervention was delivered at the day-hospital facilities in the format of group sessions (10 participants per group) offered twice a week for 12 consecutive weeks. Sessions lasted from 9:00 am to 3:30 pm (lunch and refreshments were provided and lasted 90 minutes), and the 24 sessions resulted in a total of $120 \mathrm{~h}$ of intervention $(5 \mathrm{~h}$ daily). The program consisted of the following activities for patients: cognitive rehabilitation, computer assisted cognitive training, speech therapy, occupational therapy, art therapy, physical training, physical therapy, and cognitive stimulation with reading and logic games. Each one of these activities lasted for 60-90 minutes and was offered once a week. Psycho-educational workshops and psychological support group sessions were offered to caregivers twice a week from 10:00 am to 11:30 am. Detailed information about each activity can be found in a previous publication from our group ${ }^{17}$.

From the total 54 patients with mild AD allocated to the intervention group, 8 failed to reach the experimental endpoint: three did not comply to all outcome assessment proceedings, two had difficulties arranging participation, one withdrew consent and therefore discontinued intervention, one was diagnosed with a new ill-health condition and one died.

\section{Statistical analysis}

Statistical procedures were undertaken with the Statistical Package for the Social Sciences (SPSS), 20.0 version for Windows, and significance level was defined at $5 \%(\mathrm{p}=0.05)$. All variables were initially submitted to descriptive analyzes. Categorical variables were shown with numbers and percentages. The Kolmogorov-Smirnov test was used to determine whether study variables followed a normal distribution, which supported the use of parametric tests. Independent-sample $t$ tests were used to compare mean scores at baseline. Paired-sample $t$ tests were used to compare differences (baseline vs. endpoint) in test scores between experimental group and control group. The Chi-square tests were used to compare the categorical variables.

\section{Results}

Sixty-two patients with mild AD completed the trial, being 46 in the experimental group and 16 in the control group. The sociodemographic and clinical characteristics of the participants in these two groups are summarized in table 1 . There were no significant differences in age, education level, gender, CDR scores and mean psychometric test scores at baseline between mild AD patients in experimental and control groups.

Table 1. Baseline characteristics of experimental and control patients with mild $A D$

\begin{tabular}{|l|c|c|c|}
\hline Characteristics & $\begin{array}{c}\text { Experimental } \\
(\mathrm{n}=46)\end{array}$ & $\begin{array}{c}\text { Control } \\
(\mathrm{n}=16)\end{array}$ & p-value \\
\hline $\begin{array}{l}\text { Gender } \\
\text { Male }\end{array}$ & $19(41.3 \%)$ & $6(37.5 \%)$ & $0.984^{*}$ \\
Female & $27(58.7 \%)$ & $10(62.5 \%)$ & \\
\hline Age (years) & $75.7( \pm 5.6)$ & $74.8( \pm 4.7)$ & $0.418^{* *}$ \\
\hline Education (years) & $9.4( \pm 4.8)$ & $11.0( \pm 5.1)$ & $0.325^{* *}$ \\
\hline CDR & $0.5=8(17.4 \%)$ & $0.5=7(43.7 \%)$ & $0.089^{*}$ \\
& $1.0=38(82.6 \%)$ & $1.0=9(56.3 \%)$ & \\
\hline MMSE & $23.0( \pm 2.5)$ & $23.3( \pm 3.9)$ & $0.958^{* *}$ \\
\hline GDS & $5.1( \pm 3.3)$ & $4.3( \pm 3.2)$ & $0.566^{* *}$ \\
\hline POoL-AD & $34.9( \pm 6.3)$ & $36.1( \pm 5.8)$ & $0.900^{* *}$ \\
\hline COoL-AD & $31.5( \pm 5.4)$ & $31.1( \pm 7.4)$ & $0.995^{* *}$ \\
\hline
\end{tabular}

AD: Alzheimer's disease; CDR: Clinical Dementia Rating Scale; MMSE: Mini-Mental State Examination; GDS: Geriatric Depression Scale; PQoL-AD: Patient's Quality of Life; COoL-AD: Caregiver's Quality of Life. Values given are mean \pm standard deviation or $\%$ percentage; ${ }^{*}$ Chisquare test; ${ }^{* *}$ Independent-sample t tests.

Table 2 shows the mean values and standard deviations for psychometric test scores at baseline and at the end of the study for patients with mild AD. The results indicate significant increase in MMSE scores ( $p=0.021)$, a significant reduction in GDS scores ( $p$ $<0.001)$ and improvement in patients' quality of life $(\mathrm{p}=0.003)$ according to the QoL-AD in the experimental group. No statistically significant differences in caregiver's quality of life were observed between groups. No differences were observed in endpoint vs. baseline psychometric test scores in the control group.

Table 2. Psychometric test scores at baseline and after intervention (endpoint) mild AD groups

\begin{tabular}{|c|c|c|c|c|}
\hline Variable & Group & Baseline & Endpoint & $\mathrm{p}$-value ${ }^{*}$ \\
\hline \multirow[t]{2}{*}{ MMSE } & EG & $23.0( \pm 2.5)$ & $23.6( \pm 2.9)$ & 0.021 \\
\hline & CG & $23.3( \pm 3.9)$ & $22.4( \pm 2.8)$ & 0.150 \\
\hline \multirow[t]{2}{*}{ GDS } & $E G$ & $5.1( \pm 3.3)$ & $3.7( \pm 3.0)$ & $<0.001$ \\
\hline & CG & $4.3( \pm 3.2)$ & $4.7( \pm 3.4)$ & 0.561 \\
\hline \multirow[t]{2}{*}{ POOL-AD } & EG & $34.9( \pm 6.3)$ & $36.5( \pm 5.2)$ & 0.003 \\
\hline & CG & $36.1( \pm 5.8)$ & $35.4( \pm 6.1)$ & 0.523 \\
\hline \multirow[t]{2}{*}{ COoL-AD } & $\mathrm{EG}$ & $31.5( \pm 5.4)$ & $32.5( \pm 5.7)$ & 0.262 \\
\hline & CG & $31.1( \pm 7.4)$ & $32.7( \pm 6.6)$ & 0.330 \\
\hline
\end{tabular}

EG: experimental group; CG: control group; MMSE: Mini-Mental State Examination; GDS: Geriatric Depression Scale; PQoL-AD: Patient's Quality of Life; CQoL-AD: Caregiver's Quality of Life. Values given are mean \pm standard deviation. (*) Paired Sample t-test (baseline $v s$ endpoint).

In the CIND group $(\mathrm{n}=14)$ and moderate $\mathrm{AD}$ group $(\mathrm{n}=13)$, the mean age of the patients were 72.2 and 77 years, and the patients had 10.6 years and 8.1 of schooling, respectively. In both groups there were more females (CIND group, $71.4 \%$; moderate $\mathrm{AD}$ group, $77 \%$ ). All patients in the CIND group had $\mathrm{CDR}=0.5$ and all patients in the moderate $\mathrm{AD}$ group had $\mathrm{CDR}=2.0$. 
There were small but statistically significant differences in the MMSE scores $(p=0.005)$ and GDS scores $(p=0.011)$ before and after intervention in CIND group, indicative of improvement. No statistically significant differences in psychometric test scores were apparent among patients with moderate $\mathrm{AD}$ (Table 3 ).

Table 3. Psychometric test scores at baseline and after intervention (endpoint) CIND and moderate $A D$ group

\begin{tabular}{|l|c|c|c|c|}
\hline Variable & Group & Baseline & Endpoint & p-value* \\
\hline \multirow{2}{*}{ MMSE } & CIND & $27.6( \pm 1.7)$ & $28.4( \pm 1.5)$ & 0.005 \\
\cline { 2 - 5 } & Moderate AD & $15.7( \pm 1.2)$ & $16.0( \pm 2.8)$ & 0.613 \\
\hline \multirow{2}{*}{ GDS } & CIND & $7.7( \pm 5.0)$ & $6.5( \pm 4.7)$ & 0.011 \\
\cline { 2 - 5 } & Moderate AD & $4.4( \pm 2.6)$ & $3.6( \pm 3.3)$ & 0.249 \\
\hline \multirow{2}{*}{ POoL-AD } & CIND & $30.3( \pm 7.3)$ & $31.9( \pm 9.0)$ & 0.181 \\
\cline { 2 - 5 } & Moderate AD & $34.7( \pm 6.0)$ & $36.1( \pm 5.7)$ & 0.370 \\
\hline \multirow{2}{*}{ COoL-AD } & CIND & $30.4( \pm 5.4)$ & $33.0( \pm 6.2)$ & 0.137 \\
\cline { 2 - 5 } & Moderate AD & $31.6( \pm 7.4)$ & $31.2( \pm 6.9)$ & 0.849 \\
\hline
\end{tabular}

CIND: Cognitive Impairment Without Dementia; AD: Alzheimer's disease; MMSE: Mini-Mental State Examination; GDS: Geriatric Depression Scale; PQoL-AD: Patient's Quality of Life; CQoL-AD: Caregiver's Quality of Life. Values given are mean \pm standard deviation. (*) Paired Sample t-test (baseline vs endpoint).

\section{Discussion}

The present study showed that patients with mild $\mathrm{AD}$ who received a multimodal experimental rehabilitation intervention (experimental group) had an improvement in global cognitive function and in quality of life, and a reduction in the magnitude of depressive symptoms compared to those in the control group. In the sub-set of patients with CIND, comparing the scores on these tests before and after the intervention, without a proper control group, we observed improvements in the MMSE and GDS scores. No such effects were found among patients with moderate $\mathrm{AD}$.

Our results are in agreement with the findings of previous studies, which have suggested benefits in nonpharmacological intervention in patients with cognitive impairment and mild dementia ${ }^{14,30-32}$. One study that evaluated the efficacy of two different treatments to stimulate cognitive functions in patients with mild cognitive impairment and mild dementia comparing baseline and after treatment performance with control group, showed a significant improvement in global cognitive status (MMSE) in patients with mild dementia and a significant reduction of depression symptoms (GDS) in both experimental groups ${ }^{33}$.

Although, in this study no significant statistical difference was observed in moderate $\mathrm{AD}$ group, some studies showed benefits for these patients $3,32,34$. Other study that evaluated the effect of reminiscence therapy on the cognitive status and depression in patients with mild and moderate $\mathrm{AD}$ showed statistically significant the increase in mean MMSE scores and the decrease in GDS scores in the intervention group than control group ${ }^{1}$. In a recent study of the multimodal cognitive intervention for $\mathrm{AD}$ patients reported cognitive improvement in the word-list recognition and recall tests scores in experimental group, but no found statistically significant changes in GDS, MMSE and quality of life of patients scores in the experimental group before and after treatment ${ }^{5}$.

Our findings suggest that the multimodal intervention yielded improvement in quality of life, as reported by patients with mild AD compared to controls. Similar results were also noted in the occupational therapy program for patients with mild to moderate dementia, which showed improved the short term physical performance and psychological well-being domain of quality of life, measured by the WHOQOL-BREF2. In an earlier study conducted in our group, Machado and colleagues ${ }^{35}$ suggested that psychosocial intervention may prove to be an effective strategy to enhance the quality of life of $\mathrm{AD}$ patients. In the uncontrolled set of data derived from the CIND group, we found no statistically significant differences between endpoint and baseline scores on quality of life, in accordance with another study made with older adults with mild cognitive impairment ${ }^{30}$. The absence of significant differences in quality of life self-reported by CIND patients could be related with a better stability in the social life, a different situation that that lived by patients with mild AD. Onor and colleagues ${ }^{36}$ reported that during the rehabilitation program, $\mathrm{AD}$ patients increased their socialization and created a network of alliances and mutual help.

We acknowledge the limitations of the present study. First, the relatively small sample size in the mild $\mathrm{AD}$ control group. Second, the difficulties in forming adequate control group to compare CIND and moderate AD. As the focus of our study was older adults with mild $\mathrm{AD}$, but during the recruitment phase older adults with moderate $\mathrm{AD}$ and with CIND were also referred to our service, we decided to include these subjects in the rehabilitation program and therefore in the study, but analyzing separately their results. In spite of the lack of a proper control group (i.e., subjects with a similar condition assessed at baseline and endpoint but not receiving the intervention), we believe that this preliminary set of data may help us and other researchers in future studies.

In conclusion, our perception is that the multimodal intervention provided was beneficial for patients with mild $\mathrm{AD}$ and those with CIND. In the moderate AD patients, this intervention did not prove beneficial. Future studies with larger samples and rigorous randomization methods may be necessary in this area to determine the value and cost-benefit ratio of this model of intervention.

\section{Acknowledgements}

Financial support: Fundação de Amparo à Pesquisa de São Paulo (Fapesp Grant nº 09/52825-8, Brazil), Associação Beneficente Alzira Denise Hertzog da Silva (ABADHS), JNK Empreendimentos e Incorporações.

\section{Conflict of interest}

None.

\section{References}

1. Duru Aşiret G, Kapucu S. The Effect of Reminiscence Therapy on Cognition, Depression, and Activities of Daily Living for Patients With Alzheimer Disease. J Geriatr Psychiatry Neurol. 2015. Aug 6. pii: 0891988715598233.

2. Kumar P, Tiwari SC, Goel A, Sreenivas V, Kumar N, Tripathi RK, et al. Novel occupational therapy interventions may improve quality of life in older adults with dementia. Int Arch Med. 2014;7:26.

3. Olazarán J, Reisberg B, Clare L, Cruz I, Peña-Casanova J, Del Ser T, et al. Nonpharmacological therapies in Alzheimer's disease: a systematic review of efficacy. Dement Geriatr Cogn Disord. 2010;30(2):161-78.

4. Graff MJ, Adang EM, Vernooij-Dassen MJ, Dekker J, Jönsson L, Thijssen $\mathrm{M}$, et al. Community occupational therapy for older patients with dementia and their care givers: cost effectiveness study. BMJ. 2008;336(7636):134-8.

5. Kim HJ, Yang Y, Oh JG, Oh S, Choi H, Kim KH, et al. Effectiveness of a community-based multidomain cognitive intervention program in patients with Alzheimer's disease. Geriatr Gerontol Int. 2015. Feb 5. doi: $10.1111 /$ ggi.12453.

6. do Vale FAC, Corrêa Neto Y, Bertolucci PHF, Machado JCB, da Silva DJ, Allam N, et al. Treatment of Alzheimer's disease in Brazil: I. Cognitive disorders. Dement Neuropsychol. 2011;5(3):177-8.

7. Rodakowski J, Saghafi E, Butters MA, Skidmore ER. Non-pharmacological interventions for adults with mild cognitive impairment and early stage dementia: An updated scoping review. Mol Aspects Med. 2015;43-44:38-53.

8. Schneider N, Yvon C. A review of multidomain interventions to support healthy cognitive ageing. J Nutr Health Aging. 2013;17(3):252-7.

9. Ngandu T, Lehtisalo J, Solomon A, Levälahti E, Ahtiluoto S, Antikainen $\mathrm{R}$, et al. A 2 year multidomain intervention of diet, exercise, cognitive training, and vascular risk monitoring versus control to prevent cognitive decline in at-risk elderly people (FINGER): a randomised controlled trial. Lancet. 2015;385(9984):2255-63. 
10. Sindi S, Mangialasche F, Kivipelto M. Advances in the prevention of Alzheimer's disease. F1000Prime Rep. 2015;7:50.

11. Solomon A, Mangialasche F, Richard E, Andrieu S, Bennett DA, Breteler $\mathrm{M}$, et al. Advances in the prevention of Alzheimer's disease and dementia. J Intern Med. 2014;275(3):229-50.

12. Carrié I, van Kan GA, Gillette-Guyonnet S, Andrieu S, Dartigues JF, Touchon J, et al. Recruitment strategies for preventive trials. The MAPT study (MultiDomain Alzheimer Preventive Trial). J Nutr Health Aging. 2012;16(4):355-9.

13. Richard E, Van den Heuvel E, Moll van Charante EP, Achthoven L, Vermeulen M, Bindels PJ, et al. Prevention of dementia by intensive vascular care (PreDIVA): a cluster-randomized trial in progress. Alzheimer Dis Assoc Disord. 2009;23(3):198-204.

14. Buschert VC, Giegling I, Teipel SJ, Jolk S, Hampel H, Rujescu D, et al. Long-term observation of a multicomponent cognitive intervention in mild cognitive impairment. J Clin Psychiatry. 2012;73(12):e1492-8.

15. Buschert VC, Friese U, Teipel SJ, Schneider P, Merensky W, Rujescu D, et al. Effects of a newly developed cognitive intervention in amnestic mild cognitive impairment and mild Alzheimer's disease: a pilot study. J Alzheimers Dis. 2011;25(4):679-94.

16. Kurz A, Thöne-Otto A, Cramer B, Egert S, Frölich L, Gertz HJ, et al. CORDIAL: cognitive rehabilitation and cognitive-behavioral treatment for early dementia in Alzheimer disease: a multicenter, randomized, controlled trial. Alzheimer Dis Assoc Disord. 2012;26(3):246-53.

17. Viola LF, Nunes PV, Yassuda MS, Aprahamian I, Santos FS, Santos GD, et al. Effects of a multidisciplinary cognitive rehabilitation program for patients with mild Alzheimer's disease. Clinics (Sao Paulo). 2011;66(8):1395-400.

18. Andrieu S, Coley N2, Lovestone S3, Aisen PS4, Vellas B5. Prevention of sporadic Alzheimer's disease: lessons learned from clinical trials and future directions. Lancet Neurol. 2015;14(9):926-44.

19. Craig P, Dieppe P, Macintyre S, Michie S, Nazareth I, Petticrew M. Developing and evaluating complex interventions: the new Medical Research Council guidance. Int J Nurs Stud. 2013;50 (5):587-92.

20. McKhann GM, Knopman DS, Chertkow H, Hyman BT, Jack CR Jr, Kawas $\mathrm{CH}$, et al. The diagnosis of dementia due to Alzheimer's disease: recommendations from the National Institute on Aging-Alzheimer's Association workgroups on diagnostic guidelines for Alzheimer's disease. Alzheimers Dement. 2011;7(3):263-9.

21. Fisher GG, Franks MM, Plassman BL, Brown SL, Potter GG, Llewellyn $\mathrm{D}$, et al. Caring for individuals with dementia and cognitive impairment, not dementia: findings from the aging, demographics, and memory study. J Am Geriatr Soc. 2011;59(3):488-94.
22. Chertkow H, Nasreddine Z, Joanette Y, Drolet V, Kirk J, Massoud F, et al. Mild cognitive impairment and cognitive impairment, no dementia: Part A, concept and diagnosis. Alzheimers Dement. 2007;3(4):266-82.

23. Brucki SM, Nitrini R, Caramelli P, Bertolucci PH, Okamoto IH. [Suggestions for utilization of the mini-mental state examination in Brazil]. Arq Neuropsiquiatr. 2003;61(3B):777-81.

24. Folstein MF, Folstein SE, McHugh PR. "Mini-mental state". A practical method for grading the cognitive state of patients for the clinician. J Psychiatr Res. 1975;12(3):189-98.

25. Maia AL, Godinho C, Ferreira ED, Almeida V, Schuh A, Kaye J, et al [Application of the Brazilian version of the CDR scale in samples of dementia patients]. Arq Neuropsiquiatr. 2006;64(2B):485-9.

26. Morris JC. The Clinical Dementia Rating (CDR): current version and scoring rules. Neurology. 1993;43(11):2412-4.

27. Paradela EMP, Lourenço RA, Veras RP. Validação da escala de depressão geriátrica em um ambulatório geral. Rev Saúde Pública, 2005;39(6):918-23.

28. Yesavage JA, Brink TL, Rose TL, Lum O, Huang V, Adey M, et al. Development and validation of a geriatric depression screening scale: a preliminary report. J Psychiatr Res. 1982-1983;17(1):37-49.

29. Novelli MM, Nitrini R, Caramelli P. Validation of the Brazilian version of the quality of life scale for patients with Alzheimer's disease and their caregivers (QOL-AD). Aging Ment Health. 2010;14(5):624-31.

30. Rojas GJ, Villar V, Iturry M, Harris P, Serrano CM, Herrera JA, et al. Efficacy of a cognitive intervention program in patients with mild cognitive impairment. Int Psychogeriatr. 2013;25(5):825-31.

31. Hall L, Orrell M, Stott J, Spector A. Cognitive stimulation therapy (CST): neuropsychological mechanisms of change. Int Psychogeriatr. 2013;25(3):479-89.

32. Woods B, Aguirre E, Spector AE, Orrell M. Cognitive stimulation to improve cognitive functioning in people with dementia. Cochrane Database Syst Rev. 2012;2:CD005562.

33. Talassi E, Guerreschi M, Feriani M, Fedi V, Bianchetti A, Trabucchi M. Effectiveness of a cognitive rehabilitation program in mild dementia (MD) and mild cognitive impairment (MCI): a case control study. Arch Gerontol Geriatr. 2007;44 Suppl 1:391-9.

34. Bahar-Fuchs A, Clare L, Woods B. Cognitive training and cognitive rehabilitation for persons with mild to moderate dementia of the $\mathrm{Al}$ zheimer's or vascular type: a review. Alzheimers Res Ther. 2013;5(4):35.

35. Machado F, Nunes PV, Viola LF, Santos FS, Forlenza OV, Yassuda MS Quality of life and Alzheimers disease: influence of participation at a rehabilitation center. Dement Neuropsychol. 2009;3(3):241-7.

36. Onor ML, Trevisiol M, Negro C, Signorini A, Saina M, Aguglia E. Impact of a multimodal rehabilitative intervention on demented patients and their caregivers. Am J Alzheimers Dis Other Demen. 2007;22(4):261-72. 